\title{
Commentary: The Case for Abandoning Therapeutic Chelation of Copper lons in Alzheimer's Disease
}

\author{
Rosanna Squitti ${ }^{1 *}$, Carlo Salustri ${ }^{2}$, Mauro Rongioletti $^{3}$ and Mariacristina Siotto ${ }^{4}$ \\ ${ }^{1}$ Molecular Markers Laboratory, IRCCS Istituto Centro San Giovanni di Dio-Fatebenefratelli, Brescia, Italy, ${ }^{2}$ Institute of \\ Cognitive Sciences and Technologies (CNR), Rome, Italy, '3Department of Laboratory Medicine, Research and \\ Development Division, San Giovanni Calibita-Fatebenefratelli Hospital, Rome, Italy, ${ }^{4}$ Don Carlo Gnocchi ONLUS \\ Foundation, Milan, Italy
}

Keywords: copper, Alzheimer's disease, beta-amyloid peptide, chelation therapy, metals

\section{A commentary on}

The Case for Abandoning Therapeutic Chelation of Copper Ions in Alzheimer's Disease Drew SC. Front Neurosci (2017) 11:317. doi: 10.3389/fnins.2017.00317

\section{OPEN ACCESS}

Edited by:

Stefano L. Sensi, Università degli Studi “G. d'Annunzio"

Chieti-Pescara, Italy

Reviewed by: Gianfranco Spalletta, Fondazione Santa Lucia (IRCCS), Italy

Paul Anthony Adlard, Florey Institute of Neuroscience and Mental Health, Australia

${ }^{*}$ Correspondence: Rosanna Squitti rosanna.squitti@afar.it

Specialty section: This article was submitted to Neurodegeneration, a section of the journal

Frontiers in Neurology

Received: 27 June 2017 Accepted: 08 September 2017 Published: 25 September 2017

Citation: Squitti R, Salustri C, Rongioletti M and Siotto M (2017) Commentary:

The Case for Abandoning Therapeutic Chelation of Copper Ions in Alzheimer's Disease.

Front. Neurol. 8:503. doi: 10.3389/fneur.2017.00503
Drew's paper (1) contains a helpful overview of the numerous works published on the interaction between copper and beta-amyloid $(\mathrm{A} \beta)$ in Alzheimer's disease (AD). However, his linking of the usefulness of therapeutic copper chelation in $\mathrm{AD}$ primarily to copper- $\mathrm{A} \beta$ coordination chemistry appears to us to be limited. First, A $\beta$ 's "causative" role is challenged by various types of evidence; second, one must consider that $\mathrm{AD}$ is a complex disease, contributing to the development of many risk factors.

While still trusting pathogenesis theories, such as the "amyloid cascade" (2), or the "metal hypothesis" (3), and more recent ones proposing a loss of A $\beta$ 's capability to properly handle copper (4-6), one should not overlook the literature on the relationship between AD stages and copper concentrations in serum, plasma, cerebrospinal fluid, and the brain. Many studies have investigated whether a significant difference in copper levels exists between $\mathrm{AD}$ patients and healthy individuals, and whether those levels correlate with the patient clinical picture.

Drew notes the controversies surrounding the conclusions of these studies. Nevertheless, a number of meta-analyses published in the last 5 years undoubtedly show that the copper levels are lower in $\mathrm{AD}$ brains than in healthy ones [see, e.g., the comparison of $115 \mathrm{AD}$ patients with 123 healthy controls by Ref. (7)], while the copper levels are higher in AD patients' serum [see, e.g., Wang et al.s comparison of $1,768 \mathrm{AD}$ patients with 2,514 healthy controls (8)]. Subsequent studies have shown the similar results. Three studies confirmed lower levels of copper in the brain (9-11). Considering general circulation studies, two studies reported no overall differences in outcomes, while five studies show higher levels of copper in AD patients vs. controls (Table 1). Moreover, a recent meta-analysis (12) comparing $879 \mathrm{AD}$ patients with 1712 controls has shown that the plasma copper component that circulates not bound to ceruloplasmin (non-Cp copper) is increased in $\mathrm{AD}$, as confirmed by studies published after this publication $(13,14)$.

Thus, AD appears as characterized by an aberrant copper homeostasis: higher non-Cp copper levels in the blood stream and lower levels in the brain, exactly like in Wilson disease (WD) (21), although at a much milder level. In fact, James and coworkers (22) demonstrated that in the brain areas strongly damaged by $\mathrm{AD}$, lower levels of total copper coexist with higher levels of copper not bound to proteins (non-Cp copper in the brain), as it occurs in WD. Furthermore, lower values of serum ceruloplasmin specific activity coexist with higher levels of non-Cp copper (20). In summary, a mild degree of failure of copper control appears to occur in AD. 


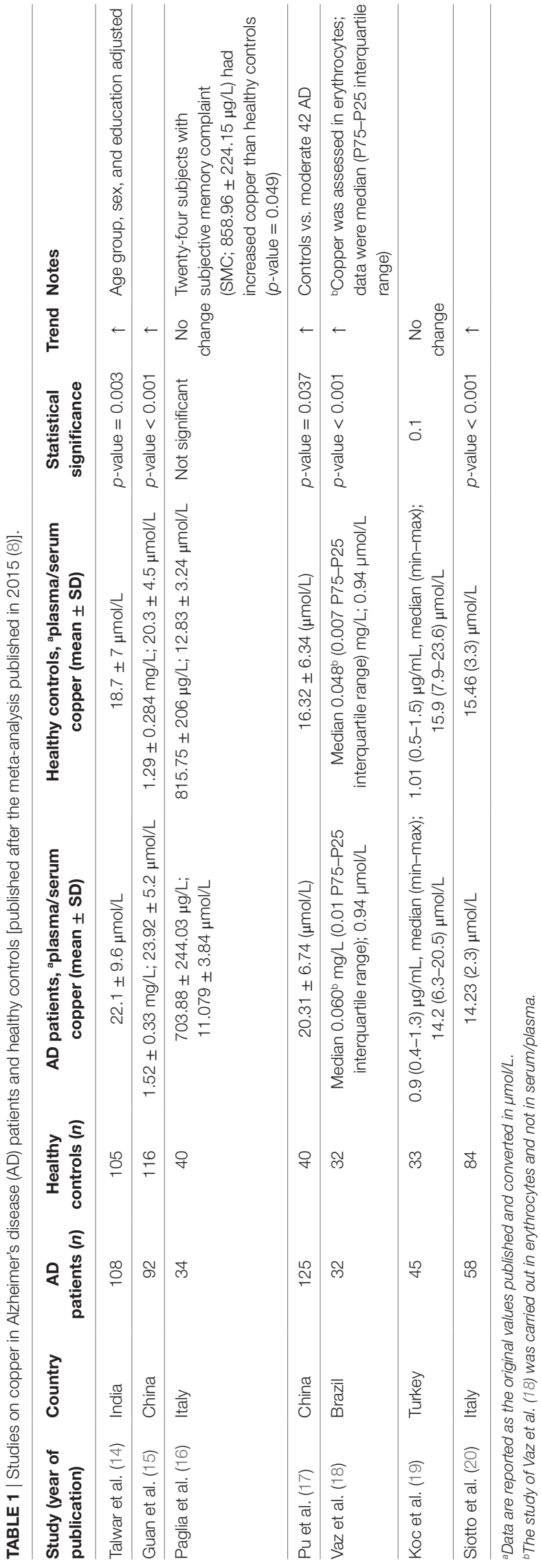

Recently, some genetic studies [reported in Ref. (23)] have contributed to our understanding by demonstrating that the presence of $A T P 7 B$ (WD) gene's variants increases (from 1.63 to 5.16 odds ratio) the risk of developing $\mathrm{AD}$. The gene's variant $K 832 R$ has been the object of a recent in-vivo study demonstrating that this $\mathrm{AD}$-related $A T P 7 B$ variant is a loss-of-function allele in Drosophila (24). Further genetic studies are in progress to verify whether $A D$ patients with higher non-Cp copper levels are also carriers of multiple rare $A T P 7 B$ gene mutations. However, should that be the case, copper toxicosis could be possibly prevented/treated with chelating or anti-copper agents, as in WD.

Moreover, Brewer has drawn attention on possible beneficial effects of more tolerable zinc-based therapies. He (25) describes post-hoc results presented by Dr. Diana Pollack at various meetings, showing zinc therapy as capable of stopping cognitive decline: by restricting Pollack's post-hoc analysis to those among her patients who were aged 70 years or older (14 zinc treated and 15 placebo treated), Brewer showed that the latter scored significantly better in the Alzheimer's Disease Assessment Scale cognitive subscale, Clinical Dementia Rating Scale Sum of Boxes, and Mini-Mental State Examination than placebo patients.

In 2002, our laboratory attempted a study on the effects of D-penicillamine (D-pen) in AD (26). Penicillamine is known to promote "de-coppering" in WD by forming copper-penicillamine complexes, which are then excreted with the urine. In our study, $77.8 \%$ of the AD patients under D-pen treatment showed a 24-h urinary excretion higher than $200 \mu \mathrm{g} / \mathrm{day}$, which is $5 \times$ the value $(40 \mu \mathrm{g} /$ day $)$ which is widely accepted as representative of a "normal" copper excretion (27). A $5 \mu \mathrm{g} /$ day $\times 40 \mu \mathrm{g} /$ day excretion is considered the "D-pen challenge test" cutoff, supportive of WD diagnosis in asymptomatic patients (28). The D-pen test, however, is not disease-specific. Individuals suffering from hepatic cirrhosis, for example, also show excretion values higher than the mentioned cutoff. In $\mathrm{AD}$ patients under D-pen treatment (26), this is suggestive of failure a copper control.

Unfortunately, when excretion reaches levels that make the copper balance negative, some patients treated with WD under D-pen treatment show a serious "iatrogenic" deterioration (often referred to as "paradoxical effect"), with an increase of the neurological symptoms. This effect is believed to be caused by a frantic mobilization and redistribution of copper which results in high copper level in the brain and in the blood $(29,30)$. Manifestation of similar neurological symptoms in our study on AD forced an early interruption (26). This is suggestive, however, of copper homeostasis abnormalities, as some authors commented (31). Nevertheless, up to that point, D-pen had shown a positive effect in reducing oxidative stress.

In conclusion, we agree with Drew that the metal- $A \beta_{1-x}$ interactions can be downstream of an underlying pathology of AD. However, we deem this not to be a valid reason for abandoning therapeutic chelation of copper ions in $A D$ that has not been yet thoroughly tested. In our opinion, anti-copper therapies appear to have excellent chances to affect positively the condition for a percentage of $\mathrm{AD}$ patients, in agreement with the notion of the existence of different AD "sub-types" (32-35). 


\section{AUTHOR CONTRIBUTIONS}

RS, CS, MR, and MS contributed to the concepts expressed in the commentary. All authors contributed to the conceptualization of the manuscript, its realization, and writing. In particular, MS evaluated the chemical coordination part of the Drew's manuscript and the clinical chemistry part of our commentary.

\section{REFERENCES}

1. Drew SC. The case for abandoning therapeutic chelation of copper ions in Alzheimer's disease. Front Neurosci (2017) 11:317. doi:10.3389/fnins.2017. 00317

2. Hardy JA, Higgins GA. Alzheimer's disease: the amyloid cascade hypothesis. Science (1992) 256(5054):184-5. doi:10.1126/science.1566067

3. Bush AI, Tanzi RE. Therapeutics for Alzheimer's disease based on the metal hypothesis. Neurotherapeutics (2008) 5(3):421-32. doi:10.1016/j. nurt.2008.05.001

4. Lee HG, Castellani RJ, Zhu X, Perry G, Smith MA. Amyloid- $\beta$ in Alzheimer's disease: the horse or the cart? Pathogenic or protective? Int J Exp Pathol (2005) 86(3):133-8. doi:10.1111/j.0959-9673.2005.00429.x

5. Cavaleri F. Paradigm shift redefining molecular, metabolic and structural events in Alzheimer's disease involves a proposed contribution by transition metals. Defined lengthy preclinical stage provides new hope to circumvent advancement of disease- and age-related neurodegeneration. Med Hypotheses (2015) 84(5):460-9. doi:10.1016/j.mehy.2015.01.044

6. Kepp KP. Alzheimer's disease: how metal ions define $\beta$-amyloid function. Coord Chem Rev (2017). doi:10.1016/j.ccr.2017.05.007

7. Schrag M, Mueller C, Oyoyo U, Smith MA, Kirsch WM. Iron, zinc and copper in the Alzheimer's disease brain: a quantitative meta-analysis. Some insight on the influence of citation bias on scientific opinion. Prog Neurobiol (2011) 94(3):296-306. doi:10.1016/j.pneurobio.2011.05.001

8. Wang ZX, Tan L, Wang HF, Ma J, Liu J, Tan MS, et al. Serum iron, zinc, and copper levels in patients with Alzheimer's disease: a replication study and meta-analyses. J Alzheimers Dis (2015) 47(3):565-81. doi:10.3233/ JAD-143108

9. House E, Esiri M, Forster G, Ince PG, Exley C. Aluminium, iron and copper in human brain tissues donated to the medical research council's cognitive function and ageing study. Metallomics (2012) 4(1):56-65. doi:10.1039/ clmt00139f

10. Graham SF, Nasaruddin MB, Carey M, Holscher C, McGuinness B, Kehoe PG, et al. Age-associated changes of brain copper, iron, and zinc in Alzheimer's disease and dementia with Lewy bodies. J Alzheimers Dis (2014) 42(4):1407-13. doi:10.3233/JAD-140684

11. Szabo ST, Harry GJ, Hayden KM, Szabo DT, Birnbaum L. Comparison of metal levels between postmortem brain and ventricular fluid in Alzheimer's disease and nondemented elderly controls. Toxicol Sci (2016) 150(2):292-300. doi:10.1093/toxsci/kfv325

12. Squitti R, Simonelli I, Ventriglia M, Siotto M, Pasqualetti P, Rembach A, et al. Meta-analysis of serum non-ceruloplasmin copper in Alzheimer's disease. J Alzheimers Dis (2014) 38(4):809-22. doi:10.3233/JAD-131247

13. Squitti R, Siotto M, Cassetta E, El Idrissi IG, Colabufo NA. Measurements of serum non-ceruloplasmin copper by a direct fluorescent method specific to Cu(II). Clin Chem Lab Med (2017) 55(9):1360-7. doi:10.1515/cclm-20160843

14. Talwar P, Grover S, Sinha J, Chandna P, Agarwal R, Kushwaha S, et al. Multifactorial analysis of a biomarker pool for Alzheimer disease risk in a North Indian population. Dement Geriatr Cogn Disord (2017) 44(1-2):25-34. doi:10.1159/000477206

15. Guan C, Dang R, Cui Y, Liu L, Chen X, Wang X, et al. Characterization of plasma metal profiles in Alzheimer's disease using multivariate statistical analysis. PLoS One (2017) 12(7):e0178271. doi:10.1371/journal.pone.0178271

16. Paglia G, Miedico O, Cristofano A, Vitale M, Angiolillo A, Chiaravalle AE, et al. Distinctive pattern of serum elements during the progression of Alzheimer's disease. Sci Rep (2016) 6:22769. doi:10.1038/srep22769
RS reviewed the meta-analysis section, and MR and CS reviewed the genetic part. CS revised English editing.

\section{FUNDING}

RS was supported by Italian Ministry of Health, Ricerca Corrente.

17. $\mathrm{Pu} \mathrm{Z,} \mathrm{Xu} \mathrm{W,} \mathrm{Lin} \mathrm{Y}, \mathrm{He} J$, Huang M. Oxidative stress markers and metal ions are correlated with cognitive function in Alzheimer's disease. Am J Alzheimers Dis Other Demen (2017) 32(6):353-9. doi:10.1177/1533317517709549

18. Vaz FNC, Fermino BL, Haskel MVL, Wouk J, de Freitas GBL, Fabbri R, et al. The relationship between copper, iron, and selenium levels and Alzheimer disease. Biol Trace Elem Res (2017). doi:10.1007/s12011-017-1042-y

19. Koc ER, Ilhan A, Zubeyde A, Acar B, Gurler M, Altuntas A, et al. A comparison of hair and serum trace elements in patients with Alzheimer disease and healthy participants. Turk J Med Sci (2015) 45(5):1034-9. doi:10.3906/ sag-1407-67

20. Siotto M, Simonelli I, Pasqualetti P, Mariani S, Caprara D, Bucossi S, et al. Association between serum ceruloplasmin specific activity and risk of Alzheimer's disease. J Alzheimers Dis (2016) 50(4):1181-9. doi:10.3233/ JAD-150611

21. Fujiwara N, Iso H, Kitanaka N, Kitanaka J, Eguchi H, Ookawara T, et al. Effects of copper metabolism on neurological functions in Wistar and Wilson's disease model rats. Biochem Biophys Res Commun (2006) 349(3):1079-86. doi:10.1016/j.bbrc.2006.08.139

22. James SA, Volitakis I, Adlard PA, Duce JA, Masters CL, Cherny RA, et al. Elevated labile $\mathrm{Cu}$ is associated with oxidative pathology in Alzheimer disease. Free Radic Biol Med (2012) 52(2):298-302. doi:10.1016/j. freeradbiomed.2011.10.446

23. Squitti R, Siotto M, Arciello M, Rossi L. Non-ceruloplasmin bound copper and ATP7B gene variants in Alzheimer's disease. Metallomics (2016) 8(9):863-73. doi:10.1039/c6mt00101g

24. Mercer SW, Wang J, Burke R. In vivo modeling of the pathogenic effect of copper transporter mutations that cause Menkes and Wilson diseases, motor neuropathy, and susceptibility to Alzheimer's disease. J Biol Chem (2017) 292(10):4113-22. doi:10.1074/jbc.M116.756163

25. Brewer GJ. Copper excess, zinc deficiency, and cognition loss in Alzheimer's disease. Biofactors (2012) 38(2):107-13. doi:10.1002/biof.1005

26. Squitti R, Rossini PM, Cassetta E, Moffa F, Pasqualetti P, Cortesi M, et al. $\mathrm{D}$-penicillamine reduces serum oxidative stress in Alzheimer's disease patients. Eur J Clin Invest (2002) 32(1):51-9. doi:10.1046/j.1365-2362.2002.00933.x

27. Roberts EA, Schilsky ML; American Association for Study of Liver Diseases (AASLD). Diagnosis and treatment of Wilson disease: an update. Hepatology (2008) 47(6):2089-111. doi:10.1002/hep.22261

28. Nicastro E, Ranucci G, Vajro P, Vegnente A, Iorio R. Re-evaluation of the diagnostic criteria for Wilson disease in children with mild liver disease. Hepatology (2010) 52(6):1948-56. doi:10.1002/hep.23910

29. Hoogenraad T. Wilson's Disease. Amsterdam, Rotterdam: Intermed Medical Publishers (2001).

30. Bandmann O, Weiss KH, Kaler SG. Wilson's disease and other neurological copper disorders. Lancet Neurol (2015) 14(1):103-13. doi:10.1016/ S1474-4422(14)70190-5

31. Hoogenraad TU. Paradigm shift in treatment of Alzheimer's disease: zinc therapy now a conscientious choice for care of individual patients. Int J Alzheimers Dis (2011) 2011:492686. doi:10.4061/2011/492686

32. Amtage F, Birnbaum D, Reinhard T, Niesen WD, Weiller C, Mader I, et al. Estrogen intake and copper depositions: implications for Alzheimer's disease? Case Rep Neurol (2014) 6(2):181-7. doi:10.1159/000363688

33. Tecchio F, Vecchio F, Ventriglia M, Porcaro C, Miraglia F, Siotto M, et al. Non-ceruloplasmin copper distinguishes a distinct subtype of Alzheimer's disease: a study of EEG-derived brain activity. Curr Alzheimer Res (2016) 13(12):1374-84. doi:10.2174/1567205013666160603001131

34. Squitti R, Simonelli I, Cassetta E, Lupoi D, Rongioletti M, Ventriglia M, et al. Patients with increased non-ceruloplasmin copper appear a distinct 
sub-group of Alzheimer's disease: a neuroimaging study. Curr Alzheimer Res (2017). doi:10.2174/1567205014666170623125156

35. Squitti R, Ventriglia M, Gennarelli M, Colabufo NA, El Idrissi IG, Bucossi S, et al. Non-ceruloplasmin copper distincts subtypes in Alzheimer's disease: a genetic study of ATP7B frequency. Mol Neurobiol (2017) 54(1):671-81. doi:10.1007/s12035-015-9664-6

Conflict of Interest Statement: RS reports personal fees in the past 3 years and other interests from Canox4drug SPA (Italy), and IGEA Research Corporation
(Miami, FL, USA) outside the submitted work. Other authors have no conflict of interest to declare.

Copyright $\odot 2017$ Squitti, Salustri, Rongioletti and Siotto. This is an open-access article distributed under the terms of the Creative Commons Attribution License (CC $B Y)$. The use, distribution or reproduction in other forums is permitted, provided the original author(s) or licensor are credited and that the original publication in this journal is cited, in accordance with accepted academic practice. No use, distribution or reproduction is permitted which does not comply with these terms. 